\title{
Extreme Adaptation to Extreme Environments in Hot Dry, Hot Sub-humid and Hot Humid Climates in Mexico
}

Luis Gabriel Gomez-Azpeitia ${ }^{1}$, Gonzalo Bojórquez-Morales ${ }^{2}$, Raúl Pavel Ruiz ${ }^{3}$, Irene Marincic ${ }^{4}$, Eduardo González ${ }^{5}$ and Adalberto Tejeda ${ }^{6}$

1. Faculty of Architecture and Design, University of Colima, Coquimatlan 28040, Mexico

2. Faculty of Architecture, Autonomic University of Baja California, Mexicali 21101, Mexico

3. Faculty of Architecture, Autonomic University of Chiapas, Tuxtla Gutierrez 29050, Mexico

4. Architecture and Design Department, University of Sonora, Hermosillo 83000, Mexico

5. Faculty of Architecture and Design, University of Zulia, Maracaibo 4011, Venezuela

6. Faculty of Electronic and Atmospheric Sciences Instrumentation, Veracruz University, Xalapa 91090, Mexico

\begin{abstract}
The paper discusses the results of a field study carried out in four cities in Mexico: Hermosillo, Mexicali, Merida and Colima, during the warmest seasons of 2006-2007. The survey is according to the adaptive approach of thermal comfort. The cities' climates are hot dry, hot sub-humid and hot humid. The respondents were inhabitants of low cost housings without air conditioning. The research was performed during warm seasons and according to ISO 10551. The measurements were processed by the common method of linear regression and also by alternative methods, useful for asymmetric climates. Individuals declared comfort at very high temperatures, either high or low humidity, therefore, the resulting neutral temperatures are higher than $30{ }^{\circ} \mathrm{C}$, except in Colima $\left(28.8{ }^{\circ} \mathrm{C}\right)$. The upper limits of comfort ranges achieved temperatures up to $35^{\circ} \mathrm{C}$. The results suggest how great is the capacity of humans to adapt to conditions as extreme as those measured in the study.
\end{abstract}

Key words: Acclimation, thermal comfort, adaptive approach, field studies.

\section{Introduction}

The results analyzed in this paper are part of a field study in which the objective was to make an assessment of low cost housing supported through Vivienda Económica, a governmental program designed to help to low-income population in Mexico. These dwellings are the cheapest alternative of housing in Mexico. The dwellings do not exceed 40 $\mathrm{m}^{2}$ and they lack air conditioning (Fig. 1).

The dwellings are made from massive common concrete blocks for walls and concrete flat slabs or joist slabs with polystyrene vaults for roofs. Therefore, the difference between the dry bulb temperatures and the globe temperatures inside the housings is lesser

Corresponding author: Luis Gabriel Gomez-Azpeitia, Dr., research fields: thermal comfort, bioclimatic architecture and urban heat island. E-mail: ggomez@ucol.mx. than $4 \mathrm{~K}$ (Kelvin), even though the housings have no insulation. However, indoor temperatures are usually high in each of the cities.

The survey was conducted from May 2006 to July 2007 on the adaptive approach, interviewing individuals inside their own dwellings and following the ISO 10551. All the interviews were conducted in naturally ventilated housings.

The first results of the research were released in 2009 at the PLEA Conference in Quebec [1, 2]. At that time, the obtained neutral temperatures corresponding to the warm seasons of some cities stood out as being too high. Indeed, surveyed individuals have said they felt comfort conditions (neither warm nor cool) at temperatures as high as 30 ${ }^{\circ} \mathrm{C}$ and even more. For that reason, this paper analyzes the outcomes from four cities in order to fully understand the explanation for these extreme results. 


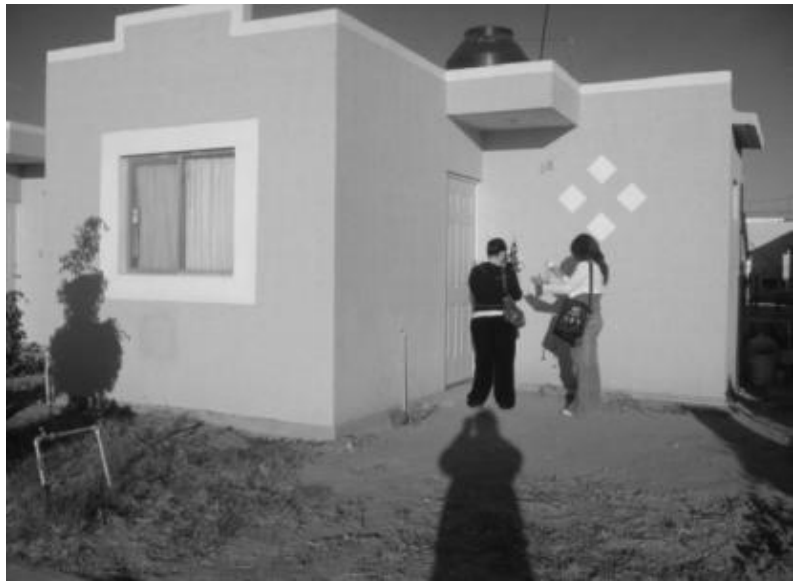

Fig. 1 Low cost housing prototype (Hermosillo, Mexico).

The climates of these cities are of the asymmetrical class. Most of the collected responses express comfort or heat, but there are no responses expressing cold. Outcomes reached by the usual method of linear regression of the data sets are unreliable for these extreme climates. The method of ATSI (averages of thermal sensation interval) [3], based in a linear regression also, but only of the average temperatures of each interval of the comfort scale, allows a more accurate approach to people's actual sensations, however, it was necessary to test the results with other procedures in order to clarify if people really were in thermal comfort at such high temperatures.

Thus, the method of Tcomf (thermal comfort temperatures) proposed by Matias et al. [4] seemed a good alternative to test our results; especially, because of that method, the individuals' thermal sensation is limited of their own preferences and tolerance judgments.

Since the number of questionnaires collected was not high for each city (between 142 and 196), we applied the Griffiths' method [5] for small samples to validate the reliability of the results.

\section{Research Area}

The results discussed in this paper come from a study conducted in four Mexican cities: Mexicali (latitude $32 \mathrm{~N}$; longitude $115 \mathrm{~W}$; altitude 4 m.s.l.) and Hermosillo (latitude 29N; longitude 110W; altitude 200 m.s.l.), both located in the northern region of the country; Colima (latitude 19N; longitude 104W; altitude 433 m.s.l.), located in the Pacific Coast; and Merida (latitude 21N; longitude $89 \mathrm{~W}$; altitude 22 m.s.l.) located near the Gulf of Mexico (Fig. 2).

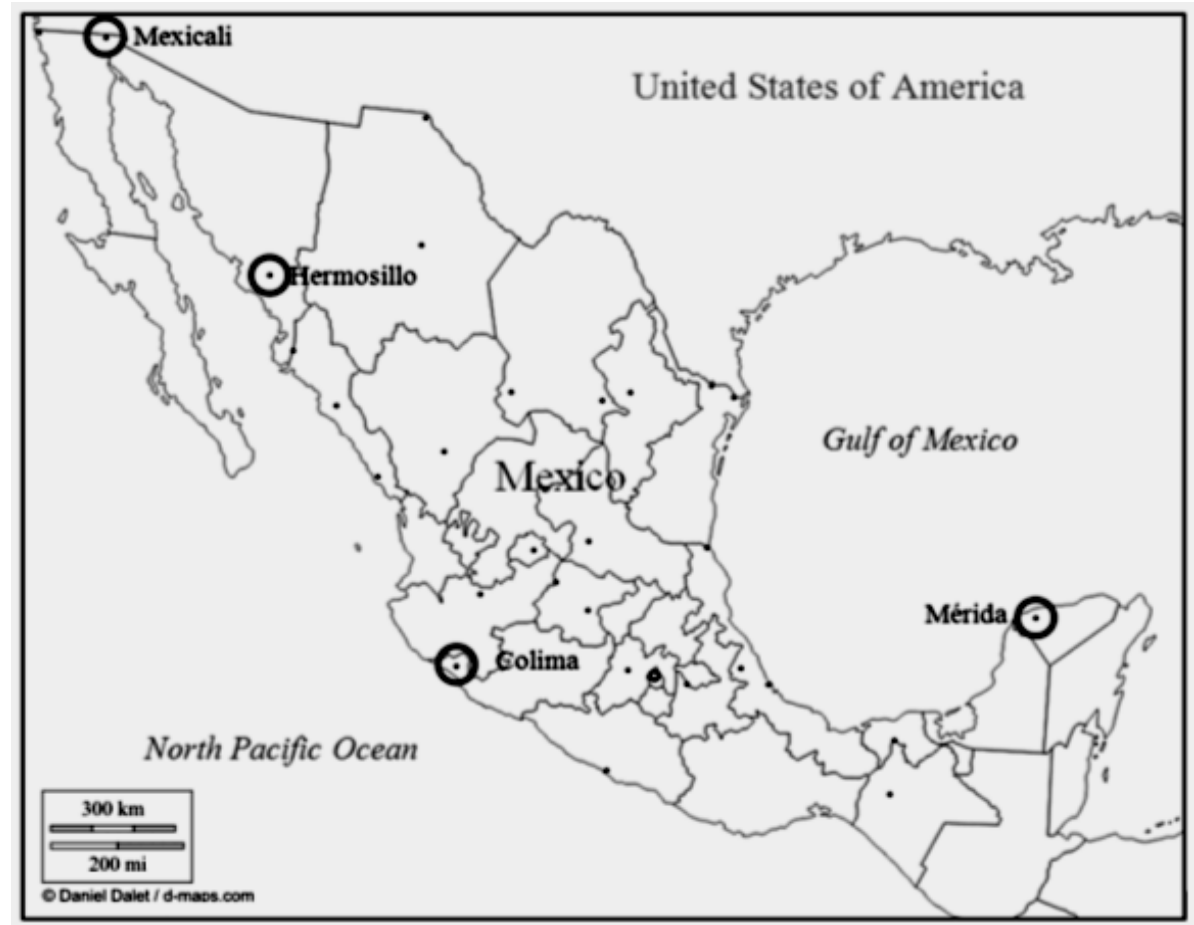

Fig. 2 Localization of the cities where the field study was carried out [6]. 
Hermosillo and Mexicali share a hot and dry climate. The average RH (relative humidity) in Hermosillo is $43 \%$ and $61 \%$ in Mexicali [7]. At noon, the RH in both cities is often below $30 \%$, but in Hermosillo, it can be lesser than $20 \%$. The thermal range of both cities oscillates between $13{ }^{\circ} \mathrm{C}$ and $19{ }^{\circ} \mathrm{C}$ during daylight hours throughout each year. The normal minimal temperatures in winter drop down to $9{ }^{\circ} \mathrm{C}$ in Hermosillo and down to $6^{\circ} \mathrm{C}$ in Mexicali. The extreme minimal temperatures may be less than $0{ }^{\circ} \mathrm{C}$. The normal maximum temperatures in summer reach up to $39{ }^{\circ} \mathrm{C}$ in Hermosillo, and can climb up to $43{ }^{\circ} \mathrm{C}$ in Mexicali. The extreme maximum temperature may be higher than $45{ }^{\circ} \mathrm{C}$. The field study data from Hermosillo were collected during the months of August and September 2006 (over $35{ }^{\circ} \mathrm{C}$ and around 33\% of $\mathrm{RH}$ at noon). The field study data from Mexicali were collected during the months of May to October 2006

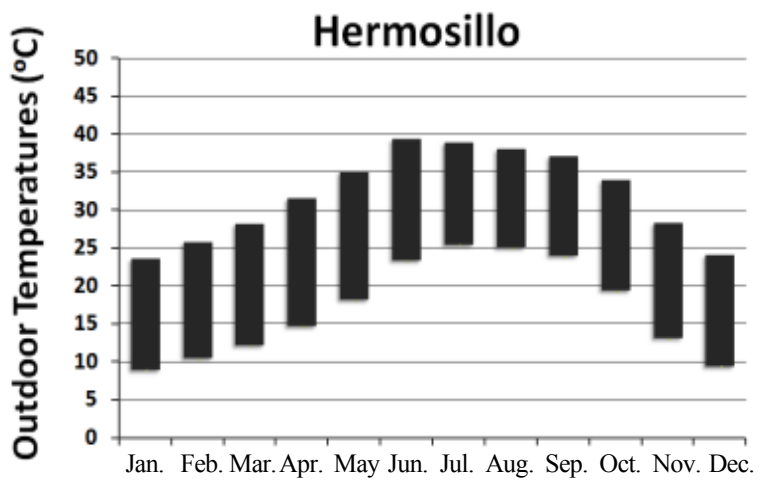

(a) Hermosillo (over $30^{\circ} \mathrm{C}$ and around $50 \%$ of RH at noon) (Fig. 3).

Colima has a warm and sub-humid climate, while Merida has a hot and humid climate. In Colima, temperatures oscillate from season to season throughout the year. The longer thermal oscillation is presented in the dry season of winter and spring (up to $16^{\circ} \mathrm{C}$ ) when the average $\mathrm{RH}$ is around $60 \%$, and the shorter oscillation in the rainy season of summer and autumn $\left(11^{\circ} \mathrm{C}\right)$ when the average $\mathrm{RH}$ is upper than $70 \%$. Spring is the warmest season. The data from Colima were collected during April and May 2007 (near to $35^{\circ} \mathrm{C}$ and $32 \%$ of $\mathrm{RH}$ at noon).

In Merida, the climate is always humid. The annual average $\mathrm{RH}$ is $73 \%$. Thus, the oscillation of temperatures remains around $15{ }^{\circ} \mathrm{C}$, which is practically the same all year long. The data from Merida were collected during the months of May to July 2007 (around $35^{\circ} \mathrm{C}$ and $50 \%$ of $\mathrm{RH}$ at noon) (Fig. 4).

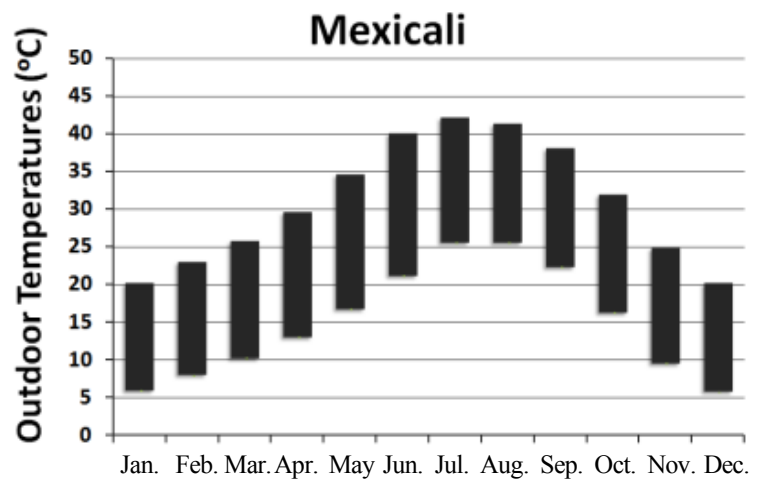

(b) Mexicali

Fig. 3 Outdoor temperatures in Hermosillo and Mexicali (hot and dry climate).

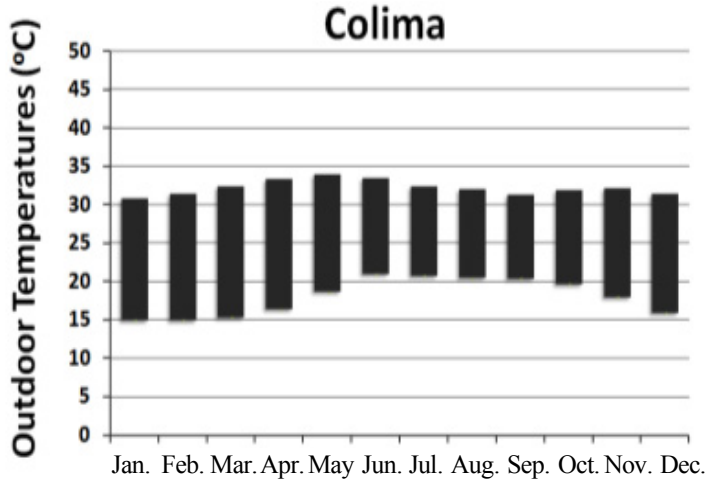

(a) Colima

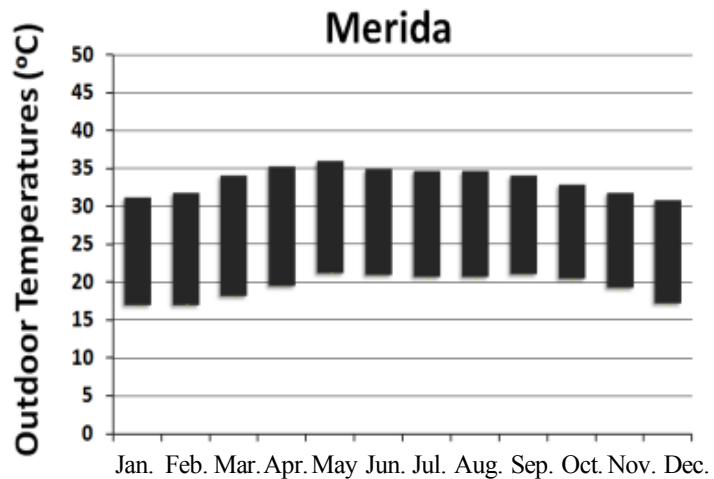

(b) Merida

Fig. 4 Outdoor temperature in Colima (warm and sub-humid climate) and Merida (hot and humid climate). 


\section{Method}

\subsection{Data Logging}

The method consists of the application of a thermal comfort questionnaire to healthy men and women between 12 and 65 years of age, and the simultaneous register of climate data. The clothing insulation level was estimated based on a classification of the type of clothing (five scales, from very light to completely clothed), and determined the average level of swaddling by sex of individuals and scale of clothing, according to the found values ISO 9920 [8].

The study sample was determined by the amount of housing units built through the financing program Vivienda Económica in each city [9]. The volunteers surveyed were chosen randomly from among the inhabitants of the selected households. As a result of the statistical case, the sample included at least 140 people per climatic season, from each city.

The respondents were individuals without any particular conditions such as pregnancy, menstrual period, chronic illness, or any other health conditions that might affect their perceived thermal sensation. The survey was approximately 50\% men and 50\% women.

The study was performed from May 2006 to July 2007. This paper covers only the warmer seasons. In order to consider a wide range of climate conditions for the study, the surveys were carried out on an occupation timetable that ran from 8:00 to 19:00 local time (Table 1).

Climatic variables were registered with thermal stress monitoring equipment called QUESTemp ${ }^{\circ} 36$ (Fig. 5). The equipment is outfitted with anemometer, air temperature, globe temperature and relative humidity sensors. The black globe thermometer is two inches in diameter. The sensors were placed at the head height of individuals $(1.1 \mathrm{~m}$ if sitting, $1.6 \mathrm{~m}$ if standing). The sensors were stabilized and ready 10 min after its installation inside the housing units. Data from all sensors were registered at the end of each survey.

Accuracy of the equipment ranges (Table 2) were within the recommendations of ISO 7726 [10]. Measurements of $T_{a}$ (ambient temperature), MRT (mean radiant temperature), and absolute humidity are Class I according to their features of range and accuracy. Measurements of air velocity are considered Class II, which is acceptable because the surveys were applied inside of free-running dwellings without air conditioning, therefore ventilation could vary widely from moment to moment.

Personal data were based on answers to a thermal comfort questionnaire, designed on ISO 10551 [11] recommendations and on suggestions from Baruch Givoni while visiting the University of Colima in 2003. The first part of the questionnaire consists of questions related to gender, age, height, weight, clothing, time spent inside, and kinds of activities carried out previous to the survey. The second part includes questions considering four kinds of judgment included in ISO 10551: thermal sensation, thermal preference, personal acceptability and personal tolerance.

Questionnaire:

- How do you feel at this exact moment? (sensation);

- At this exact moment, you would prefer to be ...? (preference);

- How do you qualify the climate inside your home? (acceptance);

- How well are you bearing the climate inside your home at this exact moment? (tolerance).

The alternatives to answer the two first questions were limited to a symmetrical seven-degree two-pole scale $(+3$ to -3$)$, as proposed by ASHRAE [12]. For the acceptance judgment, the volunteers only had two options ( 1 or 2 ), and for the tolerance judgment, they had five options, two positives ( 1 or 0 ) and three negatives (-1 to -3$)$ (Table 3 ).

Architecture students conducted the logging process (Fig. 6). The students were trained to ensure 
Table 1 Dates of measurements and number of logged responses.

\begin{tabular}{llll}
\hline City & Climate & Season & Number of responses \\
\hline Colima & Warm sub-humid & April to May 2007 & 201 \\
Merida & Hot humid & May to July 2006 & 150 \\
Hermosillo & Hot dry & August to September 2006 & 145 \\
Mexicali & Hot dry & May to October 2006 & 183 \\
\hline
\end{tabular}

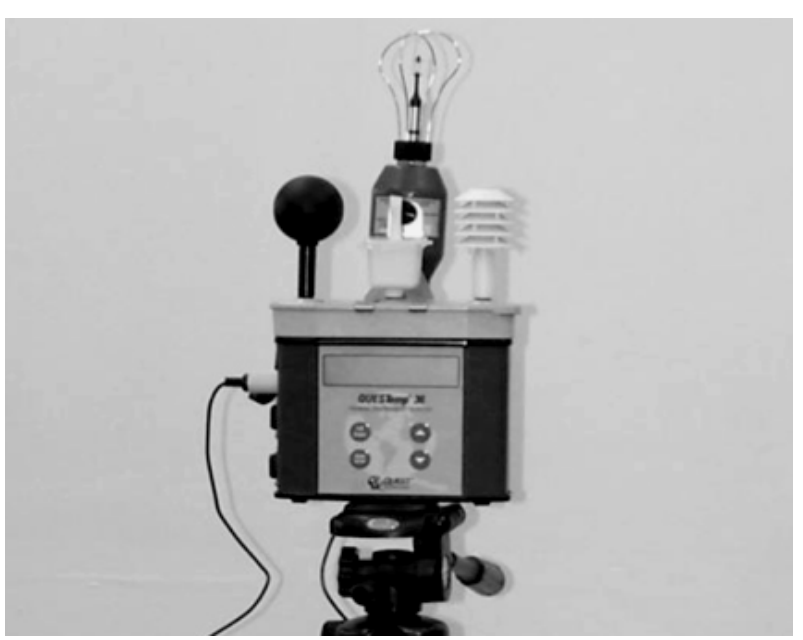

Fig. 5 Thermal stress monitor QUESTemp ${ }^{\circ} 36$.

uniformity in data collection. The research team developed a handbook for implementation of the questionnaire and registration data. The handbook served as a reference guide for all participating students.

Previous to the fieldwork, a pilot test was implemented with three specific objectives: (1) assessing the understanding level of the surveyed regarding the questions; (2) refining the performance of the students and improving their skill in the handling of the monitoring equipment; (3) estimating the average duration per each survey. With the results of this test, the necessary adjustments were made for the final implementation of the fieldwork.

\subsection{Data Processing}

In order to ensure measurement consistency, data sets were subjected to two types of testing. The first test was to find if the declared tsi (thermal sensation) was at opposite sides of the declared tpi (thermal preference). The data sets, in which the respondents said they felt warm, and they also preferred warmer temperatures, were eliminated (less than $1 \%$ on average). The second test was to find a difference between $T_{a}$ and black $T_{g}$ (globe temperature) greater than $4{ }^{\circ} \mathrm{C}$. If that situation was present, it meant that there was a heat source, perhaps from electric equipment. The data sets in which that condition occurred were eliminated (less of $0.5 \%$ on average).

Table 2 Recommended accuracy versus sensors' accuracy.

\begin{tabular}{|c|c|c|c|c|c|c|}
\hline \multirow[b]{2}{*}{ Parameter } & \multicolumn{2}{|c|}{ Class I (comfort) } & \multicolumn{2}{|c|}{ Class II (thermal stress) } & \multicolumn{2}{|c|}{ QUESTemp $^{\circ} 36$ [13] } \\
\hline & $\begin{array}{l}\text { Required } \\
\text { measurement } \\
\text { range }\end{array}$ & Required accuracy & $\begin{array}{l}\text { Required } \\
\text { measurement range }\end{array}$ & Required accuracy & Measurement range & Accuracy \\
\hline $\begin{array}{l}T_{a} \text { (ambient } \\
\text { temperature) }\end{array}$ & $10-40^{\circ} \mathrm{C}$ & $\begin{array}{l}\text { Required: } \pm 0.5 \mathrm{~K} \\
\text { Desirable: } \pm 0.2 \mathrm{~K}\end{array}$ & - & - & $0-100{ }^{\circ} \mathrm{C}$ & $\pm 0.5 \mathrm{~K}$ \\
\hline $\begin{array}{l}\text { MRT (mean } \\
\text { radiant } \\
\text { temperature) }\end{array}$ & $10-40^{\circ} \mathrm{C}$ & $\begin{array}{l}\text { Required: } \pm 2 \mathrm{~K} \\
\text { Desirable: } \\
\pm 0.2 \mathrm{~K}\end{array}$ & - & - & $0-100{ }^{\circ} \mathrm{C}$ & $\pm 0.5 \mathrm{~K}$ \\
\hline$V_{a}$ (air velocity) & - & - & $0.02-20 \mathrm{~m} / \mathrm{s}$ & $\begin{array}{l}\text { Required: } \pm 0.1+ \\
0.05 \text { va } \mathrm{m} / \mathrm{s} \\
\text { Desirable: } \pm 0.05+ \\
0.07 \text { va } \mathrm{m} / \mathrm{s}\end{array}$ & $0-20 \mathrm{~m} / \mathrm{s}$ & $\begin{array}{l} \pm 0.1+0.04 \\
\text { va } \mathrm{m} / \mathrm{s}\end{array}$ \\
\hline $\begin{array}{l}\text { Absolute } \\
\text { humidity }\end{array}$ & $0.5-3.0 \mathrm{kPa}$ & $\pm 0.15 \mathrm{kPa}$ & - & - & $\begin{array}{l}\text { Relative humidity: } \\
0-100 \% \\
0-3.16 \mathrm{kPa} \\
\left(\text { at } 25^{\circ} \mathrm{C} \text { ) }\right.\end{array}$ & $\begin{array}{l}\text { Relative } \\
\text { humidity: } \\
\pm 5 \% \\
\pm 0.15 \mathrm{kPa} \\
\left(\text { at } 25^{\circ} \mathrm{C} \text { ) }\right.\end{array}$ \\
\hline
\end{tabular}


Table 3 Scale of judgments.

\begin{tabular}{lllll}
\hline Vote $($ V) & Sensation scale ASHRAE [12] & Preference scale & Acceptance scale & Tolerance scale \\
\hline 3 & Hot & Much warmer & & \\
2 & Warm & Warmer & Generally unacceptable & \\
1 & Slightly warm & Slightly warmer & Generally acceptable & Perfectly tolerable \\
0 & Neutral & No changes & & Tolerable \\
-1 & Slightly cool & Slightly cooler & Slightly intolerable \\
-2 & Cool & Cooler & Intolerable \\
-3 & Cold & Much cooler & Extremely intolerable \\
\hline
\end{tabular}

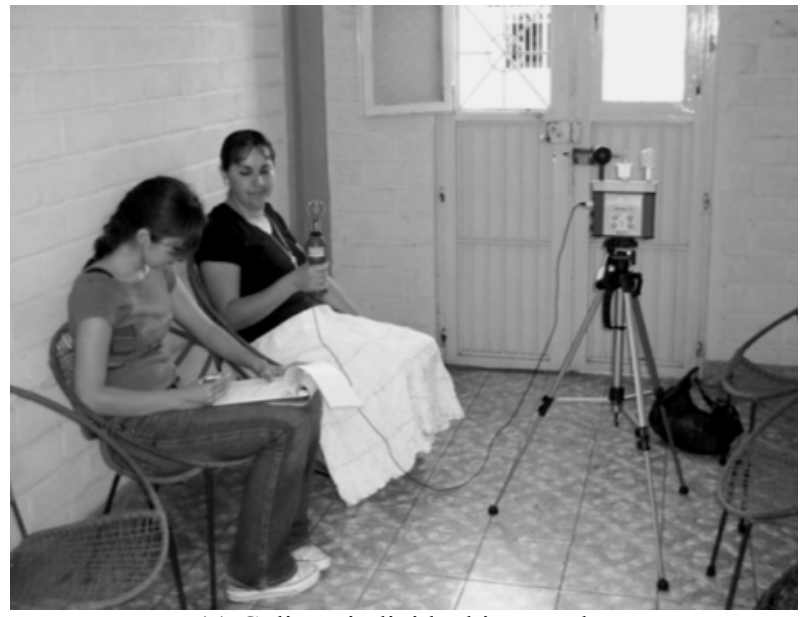

(a) Colima, individual is seated

Fig. 6 Students apply questionnaires inside the housing units.

Diverse methods were applied to data sets to determine the $\mathrm{Tn}$ (neutral temperature) and its respective $\mathrm{CR}$ (comfort range) for each season and city. The adaptive conventional procedure of lineal regression was applied to data sets of $t s i$ as well as data sets of tpi. However, since the studied cities have asymmetric climates, the thermal comfort values resulting are unreliable because the regression lines deviate towards the graph sector where there are no votes. So, the neutral temperatures obtained by this method resulted much lower to the votes of people and far of the typical temperatures of the site (Fig. 7). The limits of the comfort range are defined by the intersection of the regression line with the ordinates +1 (slightly warm) and -1 (slightly cool). Consequently, the length of the range depends on the slope of the line.

Therefore, three non-conventional methods were applied. The method of "ATSI (averages of thermal sensation intervals)" was developed by our team [3],

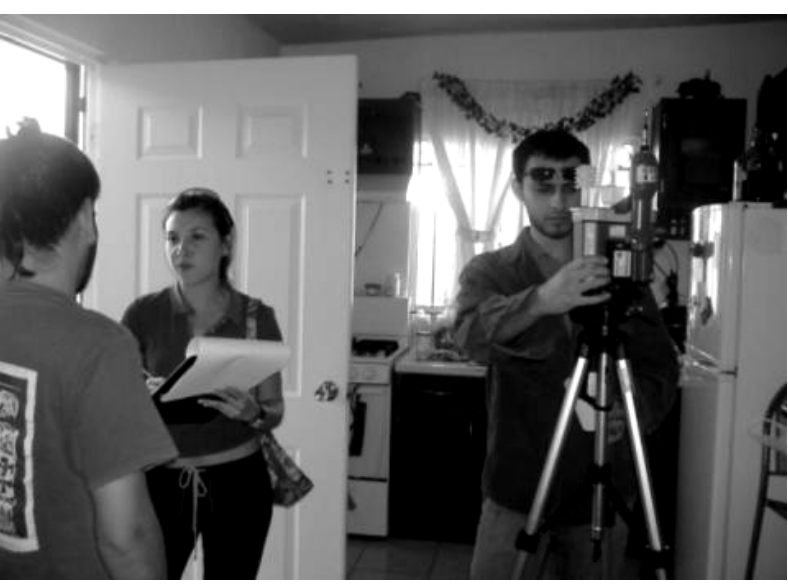

(b) Hermosillo, individual is standing

based on the analysis of mean responses proposed by Humpreys [14]. ATSI method uses descriptive statistics to determine the average and standard deviation of the voted temperatures by each one of the seven points of the comfort scale $(-3$ to +3$)$. So, the fundamental difference with the conventional method is that instead of obtaining the regression line from the complete data sets, the line comes from the mean temperatures of each category of thermal sensation. The intersection of the line with the ordinate zero (neutral votes) defines the Tn atsi (neutral temperature obtained by the ATSI method). The comfort range comes from the intersection of ordinate zero with the regression lines corresponding to the first confidence interval: mean \pm one standard deviation for each category. If the answers are near normal distribution, this range includes approximately $68 \%$ of answers that expressed comfort (neither cool, neither warm). A wider range can be defined by the regression lines 


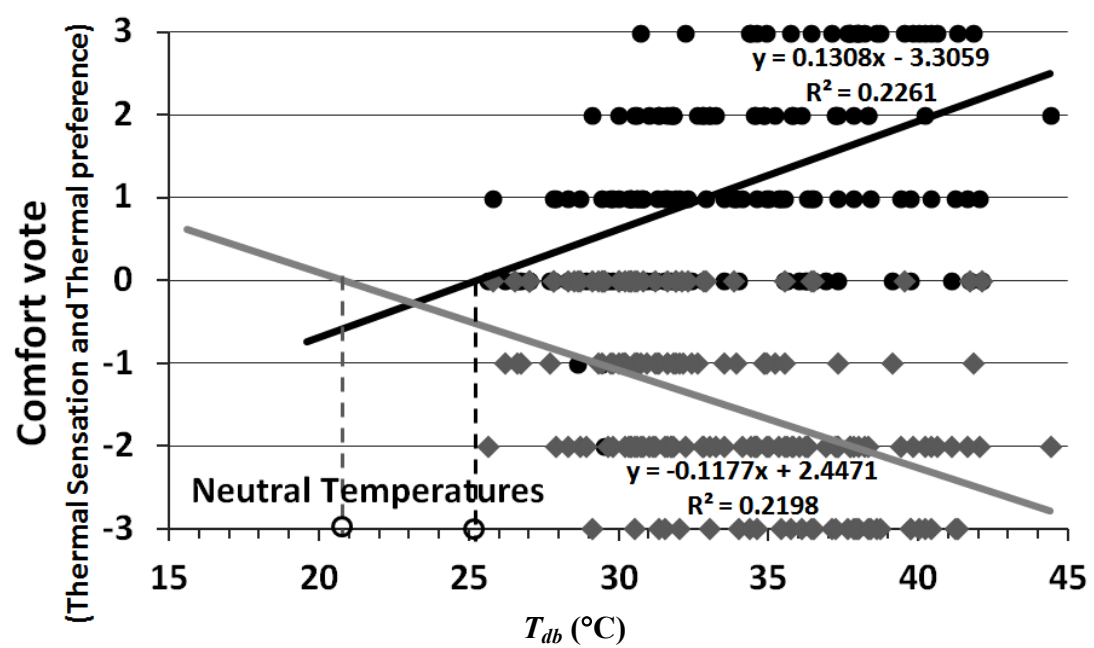

- Thermal Sensation

-Lineal (Thermal Sensation) -Lineal (Thermal preference)

Fig. 7 Determination of $T_{n}$ and CR by adaptive conventional method (example: Mexicali/May-October 2006).

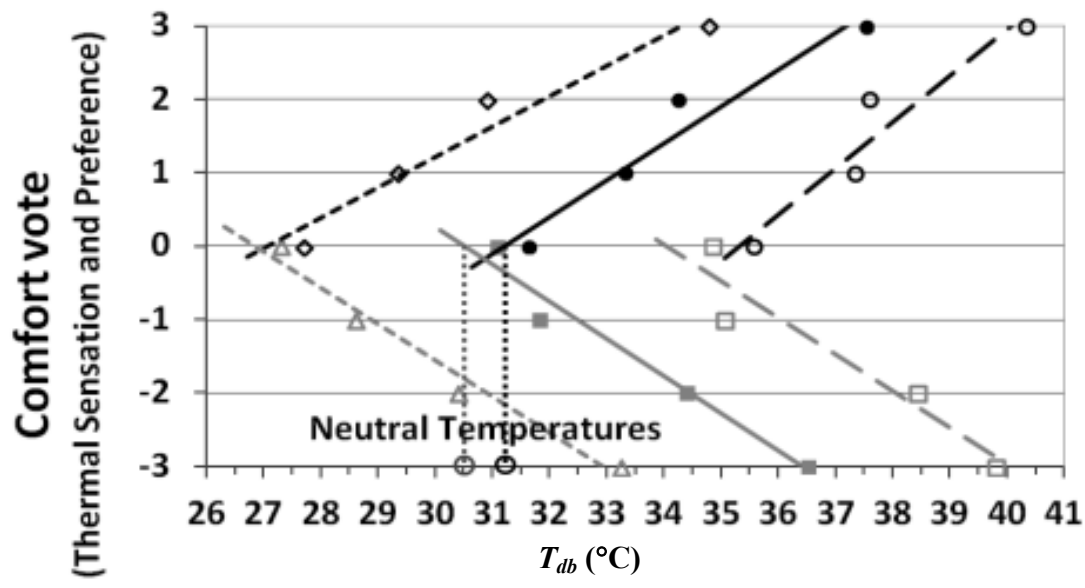

$\begin{array}{lll}\diamond \mathrm{m}-\mathrm{ds}(\mathrm{tsi}) & -\mathrm{m} \text { (tsi) } & \circ \mathrm{m}+\mathrm{ds}(\mathrm{tsi}) \\ \Delta \mathrm{m}-\mathrm{ds}(\mathrm{tpi}) & -\mathrm{m}(\mathrm{tpi}) & \square \mathrm{m}+\mathrm{ds}(\mathrm{tpi}) \\ --\cdot \text { Lineal (m - ds (tsi)) } & \text { - Lineal (m (tsi)) } & -- \text { Lineal (m + ds (tsi)) } \\ --\cdot \text { Lineal (m - ds (tpi)) } & \text { - Lineal (m (tpi)) } & -- \text { Lineal (m + ds (tpi)) }\end{array}$

Fig. 8 Determination of $T_{n}$ and CR by ATSI method (example: Mexicali/May-October 2006).

Table 4 Profiles of thermal comfort (Comf).

\begin{tabular}{lll}
\hline Profiles of comfort & $\begin{array}{l}\text { Thermal } \\
\text { sensation } \\
(t s i)\end{array}$ & $\begin{array}{l}\text { Thermal } \\
\text { preference } \\
(t p i)\end{array}$ \\
\hline Uncomfortable & $\neq 0$ & $\neq 0$ \\
Slightly uncomfortable & $=0$ & $\neq 0$ \\
Slightly comfortable & $\neq 0$ & $=0$ \\
Comfortable & $=0$ & $=0$ \\
\hline
\end{tabular}

corresponding to the second confidence interval: mean \pm two standard deviation for each interval (approximately $95 \%$ of respondents in comfort situations). In this paper, only the first range has been considered. The ATSI method was applied to data sets of $t s i$ as well as data sets of tpi (Fig. 8).

For the purpose of this paper, we also applied the alternative procedure proposed by Matias et al. [4], called "Tcomf". This method is based on tsi and tpi, leading to four distinct profiles of thermal comfort (Table 4). In turn, the profiles thus defined are tested by their corresponding responses of tolerance. The set of responses within the profile of comfort ( $t p i=0, t s i$ 
$=0)$ should have the highest average of tolerance. Obviously, the set within the profile of discomfort (tsi $\neq 0, t p i \neq 0$ ) should judge the thermal condition at the time of the survey, with the lowest level of tolerance.

In turn, the profiles thus defined are tested by their corresponding responses of tolerance. The set of responses within the profile of comfort ( $t p i=0, t s i=0$ ) has the highest average of tolerance (3.0: tolerable). Obviously, the set within the profile of discomfort ( $t s i$ $\neq 0$, tp $i \neq 0$ ) judged the thermal condition at the time of the survey, with the lowest level of tolerance (2.4: slightly intolerable) (Fig. 9).

The Tcomf temperatures, according to Matias et al. [4], correspond to indoor temperatures when tsi and tpi are null, that is, when the respondents coincide in express comfort and preference of no change (comfortable profile). In this context, we have considered as an alternative to neutral temperature, the average of temperatures recorded within the data sets with a profile of comfort: tpi and $t s i$ null. The limits of comfort ranges were defined by the maximum temperature and the minimal temperature within the above mentioned profile of comfort.

In order to reach reliable outcomes from small samples as those collected during our field study, we also applied the Griffiths' method [5]. This method is a precise procedure based on the assumption that the temperature variation for each scale point of the comfort scale is a constant equal to $3 \mathrm{~K}$ (for a seven point scale, just like the one used in this research). The constant value comes from results obtained in climate chamber experiments.

The Griffiths method consists of subtracting from each temperature value of the data sets $3 \mathrm{~K}$ times the number of scale points above the neutral vote value $(V$ $=0)$. The mean of the modified temperatures is the neutral comfort temperature for the sample $T_{n G}$ (neutral temperature obtained by the Griffiths method) Since the constant value determines the slope of the sample's regression lines, the estimation of neutral temperatures is also reached through the equation [15]:

$$
T_{n G}=T_{m}+\left(0-V_{m}\right) / a^{*}
$$

where,

$T_{n G}$ : neutral temperature by Griffiths' method;

$T_{m}$ : mean temperature when votes are recorded;

$V_{m}$ : mean thermal sensation vote $(t s i)$;

$a *$ : regression coefficient.

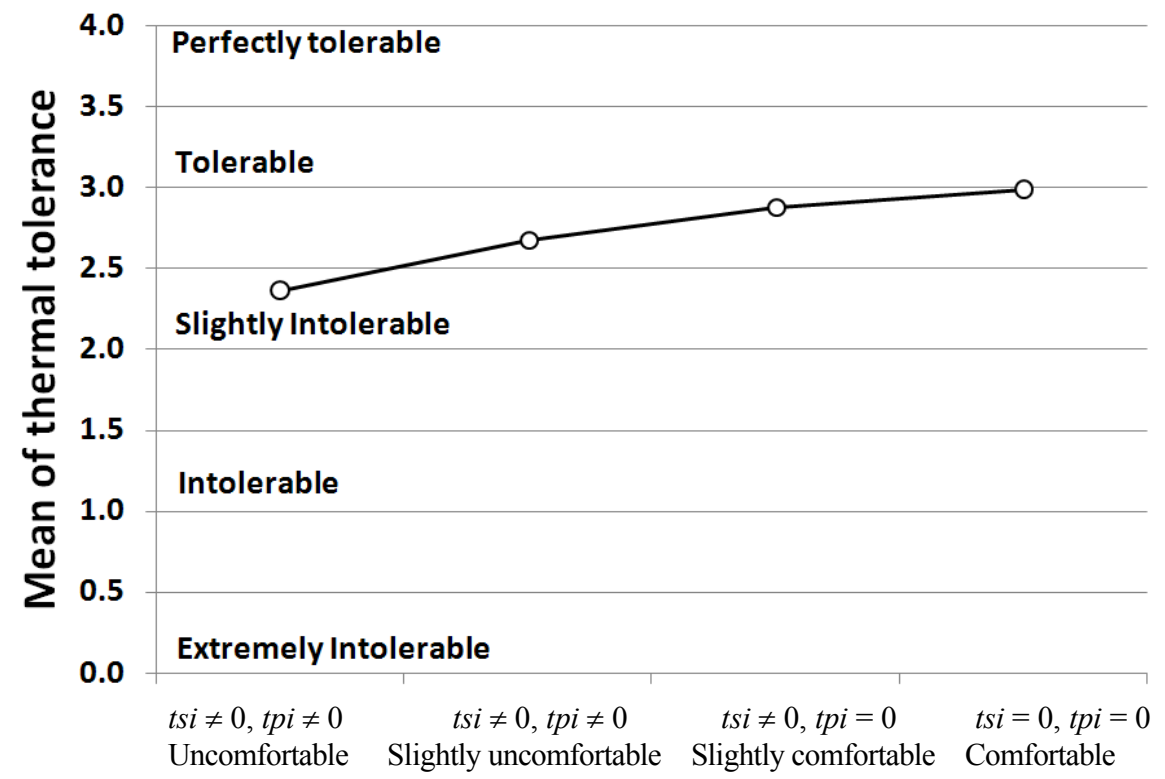

Fig. 9 Consistency test by mean of thermal tolerance (complete sample: 663 data sets). 
The $a^{*}$ is actually the slope value of the sample's regression line. If the constant value is 3 , then the slope value of the corresponding regression line is $0.33(1 / 3)$. However, the $3 \mathrm{~K}$ value is not necessarily reliable for samples from field studies. Nicol [16] said that in real situations people take adaptive actions which tend to modify the regression line's slope. Later, Nicol et al. $[17,18]$ found that a coefficient of 0.25 is often obtained in field surveys. Nevertheless, Nicol and others $[17,18]$ have preferred to use the coefficient of 0.33 , though it recognizes the need to expand our understanding of how adaptive actions can modify the regression line's slope. In this paper, we proved three regression coefficients: $0.25(1 / 4), 0.33$ $(1 / 3)$, and $0.5(1 / 2)$.

\section{Results}

Once the inconsistent data sets have been eliminated, we ended up with 663 valid data sets. 196 correspond to Colima, 150 to Merida, 143 to Hermosillo, and 174 to Mexicali. 346 correspond to a humid and sub-humid climate, and 317 correspond to a hot dry climate.

\subsection{Indoor Temperatures}

In order to determine the thermal conditions of housings at the moment of the survey, the MRT were estimated from the formula proposed by Auliciems and Szokolay [19]:

$$
M R T=\left(T_{g} \times\left(1+2.35 V_{a}\right)\right)-\left(2.35 \times T_{a} \times V_{a}\right)
$$

where,

$M R T$ : mean radiant temperature;

$T_{g}$ : black globe temperature;

$V_{a}$ : air velocity;

$T_{a}$ : ambient temperature.

In turn, $T_{o p}$ (operative temperatures) were calculated according to the simplified formula from ANSI/ASHRAE 55 [12]:

$$
T_{o p}=\left(T_{a}+M R T\right) / 2 .
$$

Fig. 10 shows that there are no significant differences between the $T_{a}$ and the $T_{o p}$. This fact can be explained by the construction materials of the buildings, based on common concrete blocks $(0.12 \mathrm{~m}$ thickness). In Colima, the roofs are made of concrete slabs ( $0.10 \mathrm{~m}$ thickness). In the other three cities, the roofs are made of joist slabs with polystyrene vaults (0.15 $\mathrm{m}$ thickness). Features of these kinds of materials and solutions bring an important thermal inertia which reduces the emissions of infrared inside the living spaces. Consequently, only the measurements of $T_{a}$ were used in the data sets for the subsequent procedures.

Mexicali was the only place where indoor temperatures exceeded $40{ }^{\circ} \mathrm{C}$. In Hermosillo and Merida, the highest temperatures reached up to $40{ }^{\circ} \mathrm{C}$ and in Colima up to $35{ }^{\circ} \mathrm{C}$. Colima has the lowest temperature of the sample, at $23{ }^{\circ} \mathrm{C}$, and Merida, the most humid site, recorded the lowest temperature, at $30{ }^{\circ} \mathrm{C}$. The cities of arid climate record the lowest temperatures at $26^{\circ} \mathrm{C}$.

\subsection{Respondents'Judgments}

Merida is the place with the most discomfort expressed by the respondents. Only $8.7 \%$ of them responded to being in comfort conditions, and only $3.3 \%$ said that they would not prefer any changes in temperature (cooler, of course). Almost half of respondents declared they tolerate the thermal condition at the time of the survey. Surprisingly, the respondents of Merida have the best acceptance of indoor climate. $70.7 \%$ said that it is generally acceptable.

The other three cities have similar levels of comfort declared. About one third of respondents said that they have a comfortable thermal sensation at the time of the survey. In Colima and Mexicali, about one fourth considered that they would not prefer changes, while in Hermosillo only $14.8 \%$ said the same. The acceptation judgment was also similar in three of the cities. About $54 \%$ to $66 \%$ of respondents said that the climate inside their homes is generally acceptable. Instead, the tolerance judgment presents greater 

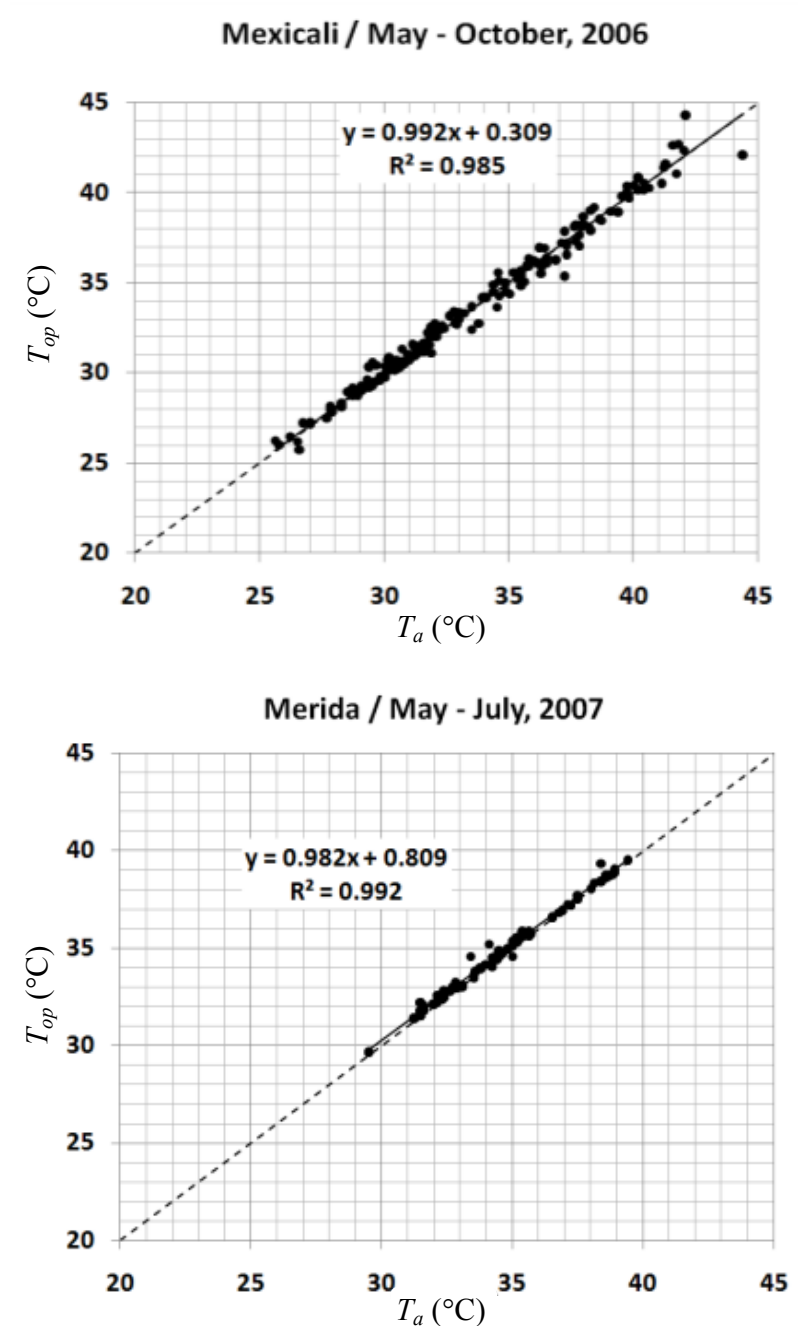

Fig. 10 Relation between $T_{a}$ and $T_{o p}$.

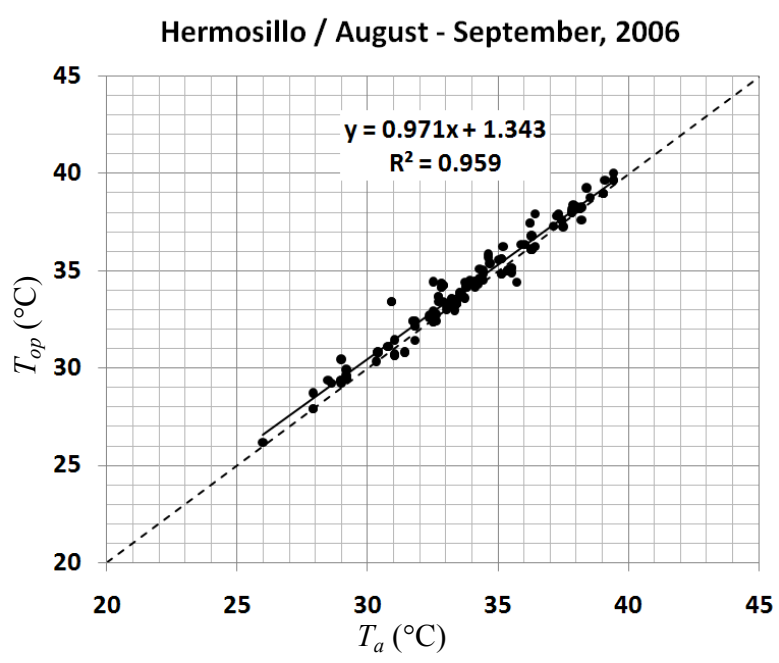

Colima / April - May, 2007

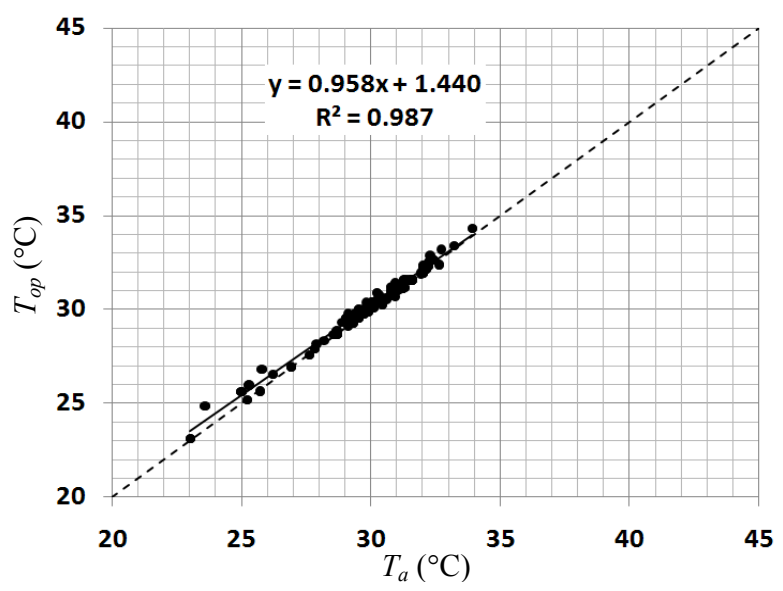

Table 5 Positive judgments.

\begin{tabular}{|c|c|c|c|c|c|c|}
\hline City & Climate & Season & Sensation & Preference & Tolerance & Acceptation \\
\hline Colima & Warm sub-humid & April to May & $30.6 \%$ & $24.0 \%$ & $76.5 \%$ & $61.7 \%$ \\
\hline Merida & Hot humid & May to July & $8.7 \%$ & $3.3 \%$ & $52.7 \%$ & $70.7 \%$ \\
\hline Hermosillo & Hot dry & August to September & $38.0 \%$ & $14.8 \%$ & $12.7 \%$ & $66.2 \%$ \\
\hline Mexicali & Hot dry & April to November & $36.2 \%$ & $23.6 \%$ & $69.0 \%$ & $54.0 \%$ \\
\hline
\end{tabular}

differences. In Colima and Mexicali, around $70 \%$ of respondents said that they tolerate the thermal condition at the time of the survey, but only $12.7 \%$ said the same in Hermosillo (Table 5).

In Fig. 11, we can see why the climate of the four cities has to be considered as asymmetric. In all the cases, more than $95 \%$ of responses of $t s i$ are distributed on the warm section of the scale. On the contrary, $100 \%$ of responses of tpi are concentrated on the cool section of the scale.

\subsection{Neutral Temperatures and Comfort Ranges}

The neutral temperatures obtained through different methods are shown in Table 6. There, we can observe that the neutral temperatures from the conventional adaptive method seem ordinary. However, they are too low, not only in respect to the declared votes of respondents, but also because they cannot explain the actual thermal regime. In these cities, the normal outdoor temperatures rarely reach as low in warm seasons. 

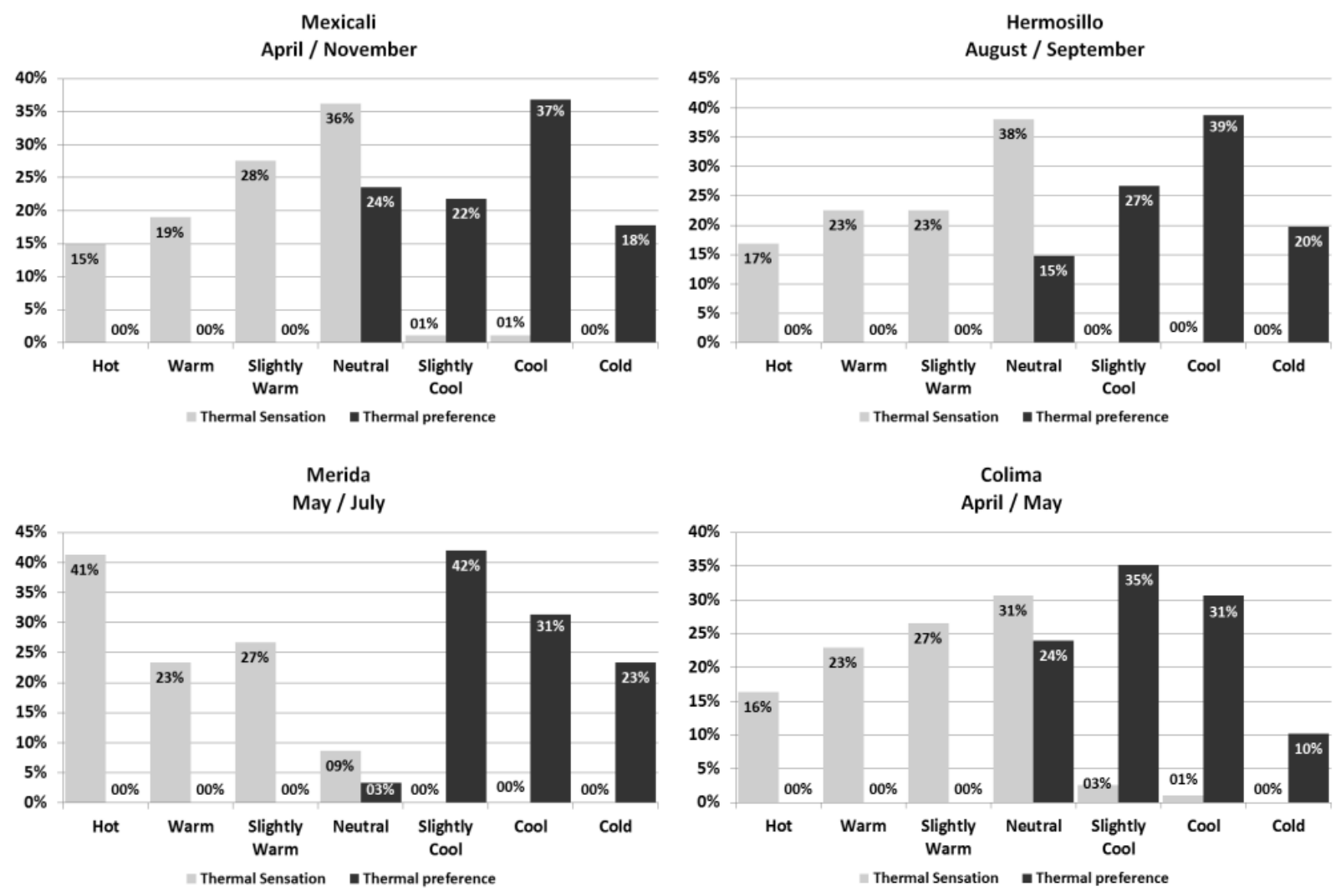

Fig. 11 The tsi and tpi distribution.

Table 6 Neutral temperatures for each city defined through data from field study.

\begin{tabular}{|c|c|c|c|c|c|c|c|c|}
\hline \multirow{4}{*}{ City } & \multirow{4}{*}{ Climate } & \multicolumn{7}{|c|}{ Neutral temperature $\left({ }^{\circ} \mathrm{C}\right)$} \\
\hline & & \multirow{3}{*}{$\begin{array}{l}\text { Adaptive } \\
\text { conventional } \\
\text { method }\left(T_{n}\right)\end{array}$} & \multicolumn{2}{|c|}{ ATSI method $\left(T_{n \text { ATSI }}\right)$} & \multirow{3}{*}{$\begin{array}{l}\text { Profiles of thermal } \\
\text { comfort (Tcomf) }\end{array}$} & \multirow{2}{*}{\multicolumn{3}{|c|}{$\begin{array}{c}\text { Griffiths method }\left(T_{n G}\right) \\
\text { Coefficient } a^{*}\end{array}$}} \\
\hline & & & \multirow{2}{*}{ Sensation } & \multirow{2}{*}{ Preference } & & & & \\
\hline & & & & & & 0.25 & 0.33 & 0.50 \\
\hline Colima & Warm sub-humid & 25.9 & 28.8 & 28.1 & 28.2 & 25.5 & 26.1 & 27.4 \\
\hline Merida & Hot humid & 22.2 & 32.3 & 33.3 & 31.4 & 26.2 & 28.1 & 30.2 \\
\hline Hermosillo & Hot dry & 27.2 & 32.3 & 33.3 & 31.9 & 29.7 & 30.2 & 31.4 \\
\hline Mexicali & Hot dry & 25.3 & 31.2 & 30.5 & 31.0 & 29.2 & 30.2 & 31.3 \\
\hline
\end{tabular}

With respect to the neutral temperatures obtained by the ATSI method, their higher values can be noted. The neutral temperature of Mexicali, Hermosillo and Merida exceed $30{ }^{\circ} \mathrm{C}$, while in Colima it exceeds 28 ${ }^{\circ} \mathrm{C}$, whether the regression was done with sensation data $(t s i)$ or was done with preference data (tpi). These are not ordinary comfort temperatures. Similar outcomes can be observed in the column of "Profiles of Thermal Comfort".

Meanwhile the neutral temperatures estimated by the Griffiths method confirm that the conventional method is not useful for asymmetric climates. Only in the case of Colima, the neutral temperature from regression $\left(T_{n}\right)$ is near the neutral temperature by Griffiths method $\left(T_{n G}\right)$ with coefficient $a^{*}$ equal to 0.25 . In the rest of the cities, the values obtained by the Griffiths method are higher than those estimated by the conventional method.

In Table 7, we can make a comparison between the results of three methods: conventional, ATSI and Griffiths, not only with respect to neutral temperatures, but with respect to regression coefficients and 
standard deviations as well. The regression coefficient in conventional method which represents the sample's slope is too low in the four cities: Mexicali 0.13 the lowest, and Colima 0.29 the highest. On the contrary, the highest regression coefficients are those related to the ATSI method. The slope value of three cities is around 1, except in Mexicali where it is 0.5 . Regarding the standard deviations, we can observe that the higher the regression coefficients, the lower the standard deviations. In all the cases, the lowest standard deviation corresponded to the ATSI method. As can be seen, even neutral temperatures obtained by Griffiths' method with a regression coefficient of 0.33 are high. In the case of the cities with hot dry climates, Hermosillo and Mexicali, neutral temperatures $T_{n G}$ are over $30^{\circ} \mathrm{C}$.

The ranges of comfort present remarkable differences (Table 8). For example, the length of ranges as a result of the adaptive conventional method is longer in respect to the length of ranges from the ATSI method. The length of the range obtained from the "Profiles" does not have regularity, because it comes from maximum and minimal temperatures in which the respondents voted in comfort, therefore, the length depends on the number of respondents (in Merida, for example, is very low: 14).

With respect to the type of climate, we can see that the length of ranges is greater in arid climates. Nonetheless, the length of the range for Merida, according to the adaptive conventional method, is the greatest. This can be explained because the slope of the regression line of the entire data sets leans toward the horizontal, so the line intersects ordinates +1 and -1 in very distant points. This is another inconsistency of this method for asymmetric climates.

Table 8 shows the difference between the limits of comfort range obtained according to the type of method. The lower limits corresponding to the adaptive conventional method are notably minor than the others. The case of Merida is especially indicative of this at around $15{ }^{\circ} \mathrm{C}$ lower. The upper limits do not show such a great difference. All the upper limits indicate that people in these climates can feel comfortable in their homes at $30{ }^{\circ} \mathrm{C}$ and even at warmer temperatures. The case of Mexicali is extreme, where some declared being comfortable at $42{ }^{\circ} \mathrm{C}$.

Table 7 Neutral temperatures $\left(T_{n}\right)$, regression coefficient $\left(a^{*}\right)$ and standard deviations $(\sigma)$ for each city according to the used method.

\begin{tabular}{|c|c|c|c|c|c|c|c|c|c|c|c|c|}
\hline \multirow{2}{*}{ Methods } & \multicolumn{3}{|c|}{ Colima } & \multicolumn{3}{|c|}{ Merida } & \multicolumn{3}{|c|}{ Hermosillo } & \multicolumn{3}{|c|}{ Mexicali } \\
\hline & $a^{*}$ & $T_{n}$ & $\sigma$ & $a^{*}$ & $T_{n}$ & $\sigma$ & $a^{*}$ & $T_{n}$ & $\sigma$ & $a^{*}$ & $T_{n}$ & $\sigma$ \\
\hline Conventional method & 0.29 & 26.0 & 2.13 & 0.17 & 22.2 & 2.29 & 0.18 & 27.2 & 2.86 & 0.13 & 25.3 & 4.15 \\
\hline ATSI method & 1.05 & 28.8 & 1.14 & 1.08 & 32.3 & 1.18 & 0.81 & 32.3 & 1.57 & 0.50 & 31.2 & 2.49 \\
\hline \multirow{3}{*}{ Griffiths' method } & 0.25 & 25.2 & 3.93 & 0.25 & 26.2 & 3.85 & 0.25 & 29.1 & 4.07 & 0.25 & 30.2 & 3.94 \\
\hline & 0.33 & 26.4 & 2.97 & 0.33 & 28.1 & 3.07 & 0.33 & 30.2 & 3.29 & 0.33 & 31.0 & 3.70 \\
\hline & 0.50 & 27.6 & 2.13 & 0.50 & 30.2 & 2.43 & 0.50 & 31.4 & 2.71 & 0.50 & 31.3 & 3.66 \\
\hline
\end{tabular}

Table 8 Comfort range for each city defined through data from field study.

\begin{tabular}{|c|c|c|c|c|c|c|c|c|c|c|c|c|c|}
\hline \multirow{4}{*}{ City } & \multirow{4}{*}{ Climate } & \multicolumn{12}{|c|}{ Comfort ranges $\left({ }^{\circ} \mathrm{C}\right)$} \\
\hline & & \multirow{2}{*}{\multicolumn{3}{|c|}{$\begin{array}{l}\text { Adaptive conventional } \\
\text { method }\end{array}$}} & \multicolumn{6}{|c|}{ ATSI method } & \multirow{2}{*}{\multicolumn{3}{|c|}{$\begin{array}{l}\text { Profiles of thermal } \\
\text { comfort }\end{array}$}} \\
\hline & & & & & \multicolumn{3}{|c|}{ Sensation } & \multicolumn{3}{|c|}{ Preference } & & & \\
\hline & & $\begin{array}{l}\text { Lower } \\
\text { limit }\end{array}$ & $\begin{array}{l}\text { Upper } \\
\text { limit }\end{array}$ & Length & $\begin{array}{l}\text { Lower } \\
\text { limit }\end{array}$ & $\begin{array}{l}\text { Upper } \\
\text { limit }\end{array}$ & Length & $\begin{array}{l}\text { Lower } \\
\text { limit }\end{array}$ & $\begin{array}{l}\text { Upper } \\
\text { limit }\end{array}$ & Length & $\begin{array}{l}\text { Lower } \\
\text { limit }\end{array}$ & $\begin{array}{l}\text { Upper } \\
\text { limit }\end{array}$ & Length \\
\hline Colima & Warm sub-humid & 22.6 & 29.4 & 6.8 & 26.6 & 31.1 & 4.5 & 25.8 & 30.4 & 4.6 & 23.0 & 31.2 & 8.2 \\
\hline Merida & Hot humid & 15.8 & 32.5 & 16.7 & 30.4 & 33.6 & 3.2 & 30.8 & 35.6 & 4.8 & 31.2 & 35.0 & 3.8 \\
\hline Hermosillo & Hot dry & 21.7 & 32.8 & 11.1 & 29.6 & 35.0 & 5.4 & 30.6 & 36.1 & 5.5 & 28.6 & 35.7 & 7.1 \\
\hline Mexicali & Hot dry & 17.6 & 32.9 & 15.3 & 27.1 & 35.3 & 8.2 & 26.9 & 34.0 & 7.1 & 26.5 & 42.1 & 15.6 \\
\hline
\end{tabular}


Table 9 Neutral temperatures for each city defined through data from field study.

\begin{tabular}{|c|c|c|c|c|c|c|}
\hline \multirow[b]{2}{*}{ City } & \multirow[b]{2}{*}{ Climate } & \multirow[b]{2}{*}{$\begin{array}{l}T_{o} \text { (outdoor } \\
\text { temperature) }\end{array}$} & \multicolumn{4}{|c|}{ Neutral temperature $\left({ }^{\circ} \mathrm{C}\right)$} \\
\hline & & & $\begin{array}{l}\text { Humpreys formula: } \\
T_{n}=11.9+0.534\left(T_{o}\right)\end{array}$ & $\begin{array}{l}\text { Auliciems formula: } \\
T_{n}=17.6+0.31\left(T_{o}\right)\end{array}$ & $\begin{array}{l}\text { Braguer and de Dear } \\
\text { formula } \\
T_{n}=17.8+0.31\left(T_{o}\right)\end{array}$ & $\begin{array}{l}\text { Field } \\
\text { study }\end{array}$ \\
\hline Colima & Warm sub-humid & 25.6 & 25.6 & 25.5 & 25.7 & 28.1 \\
\hline Merida & Hot humid & 28.2 & 26.9 & 26.3 & 26.5 & 32.3 \\
\hline Hermosillo & Hot dry & 31.1 & 28.5 & 27.2 & 27.4 & 32.3 \\
\hline Mexicali & Hot dry & 32.8 & 29.4 & 27.8 & 28.0 & 31.2 \\
\hline
\end{tabular}

\section{Discussion}

The neutral temperatures and the limits of comfort ranges obtained in this field study are higher than those that we would have expected. In fact, if we solve some of the typical equations of the adaptive approach, the obtained neutral temperature results are clearly lower among the neutral temperature from the field study (Table 9).

The effect of humidity on individual's thermal sensation is very clear in the case of Merida, the most humid city of the study. The Merida sample has the maximum percentage of individuals that prefer a cooler temperature $(96.7 \%)$, even those who have voted neutral. Indeed, the percentage of individuals that voted neutral is also minimal $(8.7 \%)$. Curiously, Merida's average outdoor temperature is almost $3{ }^{\circ} \mathrm{C}$ lower than Hermosillo. However, the neutral temperature for both cities is equal. The survey in Hermosillo, with a dry climate, declared the lower percentage of tolerance of the sample (12.7\%).

In each case the level of acceptance of the temperature inside the dwellings is surprisingly high (between 54\% and 70\%) despite the high neutral temperatures obtained, the high expectations to cooler conditions, and the low level of tolerance. How is it possible that people qualify the climate inside their homes as "generally acceptable", while they prefer cooler conditions, or they declare little tolerance, at the time of responding to the questionnaire?

There is a contradiction because less than one third of individuals declared being in conditions of comfort, while over one half of them declared the climate in their homes as acceptable. It is clear that the inhabitants of low cost housing have acclimated to their high indoor temperatures, both in high and low humidity.

\section{Conclusions}

Adaptation is the key word to understanding the results of this field study. Such results show how far the acclimation process in human beings can go, as in extreme environments such as low cost housings in hot dry, warm sub-humid and hot humid climates. Always people do something, consciously or unconsciously, to adapt to their environmental conditions. Their bodies undergo acclimation, but also their interaction with the environment provides skills that help them to improve its conditions. At the end, people agree their thermal environment, even if they have such extreme conditions as the analyzed here.

The architectural design of these dwellings lacks of bioclimatic criteria. Actually, we can find the same prototypes in all the climatic regions of the country. So, the results shown in this paper could be misunderstood that it does not matter to include bioclimatic criteria in the design of these low cost dwellings, because people would adapt anyway. On the contrary, these results must highlight the need to improve the quality of the dwellings, mainly in terms of indoor thermal comfort and energy savings. The results of this research must drive us to seek better ways to provide a suitable living environment for all people, especially those that have less money.

\section{Acknowledgments}

The authors wish to express our appreciation for each and every one who collaborated in the fieldwork, 
especially to M. Perez who headed the team at Merida. Also we wish to express our gratitude to Prof. B. Givoni for his suggestions during the first stage of the project. Finally, we express our recognition to CONAVI (National Council of Housing) and CONACYT (National Council of Science and Technology) for giving subsidy to the research project "Thermal Comfort and Energy Savings in Low-Cost Housing in Mexico: Hot Dry and Warm Humid Climates (CONAFOVI 2004-01-20)"; as well as the Fund Ramon Alvarez Buylla of University of Colima that granted additional support to the fieldwork in Colima.

\section{References}

[1] G. Gomez-Azpeitia, G. Bojorquez, P. Ruiz, R. Romero, J. Ochoa, M. Pérez, et al., Comfort temperatures inside low-cost housing case: Six warm climate cities in Mexico, in: Proceedings of 26th Conference on Passive and Low Energy Architecture, Quebec City, Canada, June 22-24, 2009.

[2] I. Marincic, J.M. Ochoa, M.G. Alpuche, G. Gomez-Azpeitia, Adaptive thermal comfort in warm dry climate: Economical dwellings in Mexico, in: Proceedings of 26th Conference on Passive and Low Energy Architecture, Quebec City, Canada, June 22-24, 2009.

[3] G. Gómez-Azpeitia, P. Ruiz, G. Bojórquez, R. Romero, Monitoring of Thermal Comfort Conditions, Technical report CONAFOVI 2004-01-20, Colima, Mexico, 2007. (in Spanish)

[4] L. Matias, S. Almeida, C. Pina Santos, M. Rebelo, M.C. Guedes, Adaptive thermal comfort for buildings in Portugal based on occupants' thermal perception, in: Proceedings of 26th Conference on Passive and Low Energy Architecture, Quebec City, Canada, June 22-24, 2009.

[5] I. Griffiths, Thermal Comfort Studies in Buildings with Passive Solar Features, Field studies report, Commission of the European Community, ENS35 090 UK, 1990.

[6] Map of Mexico Home Page, http://d-maps.com/carte.php?lib=mexico_mapa\&num_car $=22295$ \&lang $=$ es (accessed Jan. 15, 2012).

[7] A. Luna, Design and evaluation of energy sustainable housing, Ph.D. Thesis, Engineering Institute, Autonomic University of Baja California, Mexicali, 2008. (in Spanish)

[8] ISO 9920:2009, (E) Ergonomics of the Thermal Environment-Estimation of Thermal Insulation and Water Vapor Resistance of a Clothing Ensemble, International Organization for Standardization, Geneva, 2009.

[9] R. Romero, E. Vázquez, G. Bojórquez, R. Gallegos, M. Corral, A. Luna, Characterization of Low Cost Housing in Mexico in Warm Climates (Dry and Wet), Technical report CONAFOVI 2004-01-20, Mexicali, 2007. (in Spanish)

[10] ISO 7726, Ergonomics of the Thermal Environment: Instruments of Measuring Physical Quantities, ISO (International Organization for Standardization), Switzerland, 1998.

[11] ISO 10551, Ergonomics of the Thermal Environment: Assessment of the Influence of the Thermal Environment Using Subjective Judgement Scales, ISO (International Organization for Standardization), Switzerland, 1995.

[12] ANSI/ASHRAE Standard 55-04, Thermal Environmental Conditions for Human Occupancy, Atlanta GA, American Society of Heating Refrigeration and Air-Conditioning Engineers, 2010.

[13] Quest Technologies, QUESTemp ${ }^{\circ} 36$ Thermal Environment Monitor Operator's Manual, Oconomowoc, WI 53066 USA, 2004.

[14] M. Humpreys, Field studies of thermal comfort compared and applied, Building Services Engineer 44 (1976) 5-27.

[15] H.B. Rijal, H. Yoshida, Winter thermal comfort of residents in the Himalaya region of Nepal, in: Comfort and Energy Use in Buildings: Windsor Conference 2006, Cumberland Lodge, Windsor, UK, Apr. 27-30, 2006.

[16] F. Nicol, Thermal Comfort "A Handbook for Field Studies toward an Adaptive Model", University of East London, London, UK, 1993.

[17] F. Nicol, G.N. Jamy, O. Sykes, M. Humphreys, S. Roaf, M. Hancock, A survey of thermal comfort in Pakistan toward new indoor temperature standards, Working Paper, School of Architecture, Oxford Brookes University, 1994.

[18] F. Nicol, S. Roaf, Pioneering new indoor temperature standards: The Pakistan project, Energy and Buildings 23 (1996) 169-174.

[19] A. Auliciems, S.V. Szokolay, Thermal Comfort, Note 3, Passive and Low Energy Architecture International, Design Tools and Techniques, Australia, 2007. 